\title{
Utilization of Reactive Oxygen Species Generated by Electric Discharge in Biomedical Engineering
}

\author{
A.Vodickova ${ }^{a, *} \&$ J. Schmiedberger ${ }^{b}$ \\ ${ }^{a}$ Czech Technical University in Prague, Faculty of Biomedical Engineering, Department of Natural

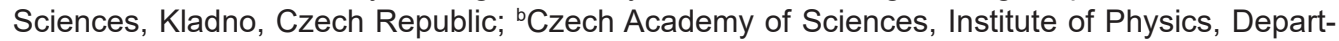 \\ ment of Radiation and Chemical Physics, Prague, Czech Republic \\ *Address all correspondence to: Anna Vodickova, Czech Technical University in Prague, Faculty of Biomedical Engineering, \\ Department of Natural Sciences, Kladno, Czech Republic; Fax: 00420224359 915, E-mail: vodicann@fbmi.cvut.cz
}

\begin{abstract}
The discharge singlet oxygen generator-6 (DSOG-6) is a device generating reactive oxygen and nitrogen species (including singlet oxygen, ozone, atomic oxygen, $\mathrm{NO}_{x}$ ) by a hybrid RF/DC electric discharge. These reactive species are often used in biomedicine. In this study, reactions of selected cell cultures (B16, HT29, and HaCat) with DSOG-6-generated particles were observed and analyzed. Cell cultures were exposed to singlet oxygen or reactive oxygen species generated by a hybrid electric discharge for different time periods. After the exposure, a microscopic analysis of the cytomorphology of cells was performed. Furthermore, cell proliferation of the B16 cell line was investigated by the xCELLigence System (Acea Biosciences Inc., San Diego, CA). Finally, preliminary results of qPCR from B16 exposed to singlet oxygen are presented. The main goal of this study was to evaluate if singlet oxygen/reactive oxygen species generated by DSOG-6 could be used in biomedical application (concretely in oncology and dermatology) and if DSOG-6 could become a new biomedical device. The secondary aim was to observe the dependence of cell lines' behavior on exposure parameters (e.g., time intervals and particles in discharge).
\end{abstract}

KEY WORDS: discharge singlet oxygen generator, singlet oxygen, cell lines, oncology, reactive oxygen species

\section{INTRODUCTION}

Singlet oxygen is the lowest electronically excited state of molecular oxygen. Its energy is about $1 \mathrm{eV}$. In medicine singlet oxygen is mainly used for purposes of photodynamic therapy. Photodynamic therapy is based on application of a photosensibilisator to the lesions and its activation by the light with a wavelength appropriate to the absorption maximum of the photosensibilisator. The result of this process is production of the singlet oxygen and the other reactive species. These species cause apoptosis of cells.

The majority of studies ${ }^{1-4}$ published in this field have used another way of singlet oxygen production - the electrically produced gas plasma is used for treatment of lesions/pathologies/wounds in a contact with plasma itself. In our case only plasma afterglow is used. Therefore, a variety of different electrically neutral particles can be selectively generated. We can switch between singlet oxygen and the other reactive oxygen species, including singlet oxygen accompanied by $\mathrm{NO}_{x}$. 
Our experimental set-up generates gaseous singlet oxygen by an electric flowing discharge; therefore, no other chemicals are needed. The aim of this study was to carry out pilot experiments that would ascertain whether our new method with generation of "electric discharge" gaseous singlet oxygen is appropriate for medical purposes, namely in oncology for melanoma treatment. For the first experiment B16 (mouse melanoma cell), HT29 (human colorectal cancer cell), and HaCat (human keratinocytes) were selected.

\section{MEIHODS}

\section{A. Experimental Set-Up}

Because discharge singlet oxygen generator-6 is a hybrid RF/DC plasmatron (RF discharge sustained DC discharge), gaseous singlet oxygen is generated by an electric discharge via electron impact (Fig. 1)..$^{5-7}$

The principle of DSOG-6 is fast mixing of argon hybrid RF/DC plasma jet with a neutral oxygen stream - energy transfer from the Ar hybrid plasma jet to a neutral oxygen

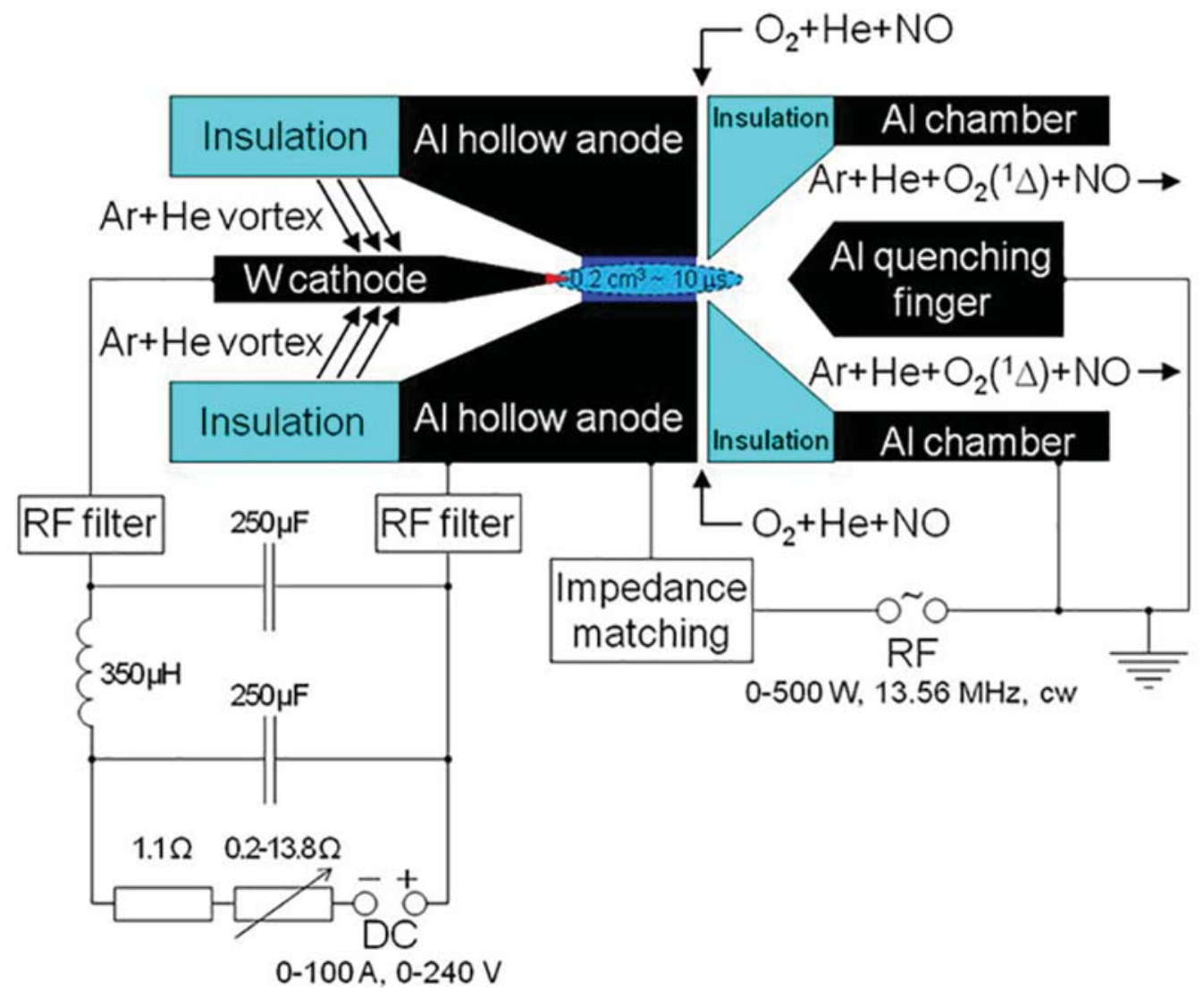

FIG. 1: DSOG-6 scheme 
stream. The functionality of DSOG-6 plasmatron is described in detail in previous publications..$^{5-7}$

Currently the applicability of the set-up for in situ medical applications is limited due to low pressure in the exposure chamber. Nevertheless it has been proved that the low pressure does not affect the investigated in vitro cell cultures in our study. The conditions in the exposure chamber are as follows: low pressure about $1300 \mathrm{~Pa}$; temperature approximately $27^{\circ} \mathrm{C}$; and exposure gases - discharge gases $(\mathrm{NO}, \mathrm{O} 2, \mathrm{He}$, Ar), singlet oxygen, reactive oxygen species, NOx.

\section{B. Cell Cultures}

B16-RGF/GFP animal cell line models of cancer (mouse melanoma cells) were the first set of samples. Because gaseous singlet oxygen is suitable for surface applications only a cell culture living on the skin was required. These preliminary experiments served for methodology optimization; that is, setting device parameters, estimation of suitable exposure times, and the low pressure effect on the cell cultures.

After the exposure methodology improvement, the first series of experiments using human cell lines HT29 and HaCat were performed.

\section{Methodology}

Cell lines were cultivated with RPMI-1640 complemented with vitamins, fetal bovine serum (FBS), and antibiotics. They were cultivated in an incubator tempered to $37^{\circ} \mathrm{C}$ and $5 \%$ atmosphere of $\mathrm{CO}_{2}$. When $80 \%$ confluence of cells on the bottoms of these flasks was achieved, the cells were passaged to Petri dishes. Before the exposure by singlet oxygen the cells were exposed with clear RPMI (without any vitamins or antibiotics). Figure 2 shows microscopy images of the used cell lines.

For the experiments with B16 cell lines (mouse melanoma cell line) the exposed medium was flushed out after experiments and a fresh medium was put in the dishes immediately. The exposure times and used particles for cell culture are illustrated in Table 1.

The methodology used in the case of HT29 (human colorectal cancer cell line) and HaCat (human keratinocytes) cell cultures is illustrated in Fig. 3.

\section{EVALUATION METHODS}

The cell viability and cytomorphology were estimated using microscopy techniques and evaluated by trypan blue assay. The B16 cell lines were further analyzed using the xCELLigence system. Statistical evaluation for validation/negation of hypothesis (the cells after exposure to singlet oxygen are dying) was carried out using GraphPad Prism 5.0 software (GraphPad Software, Inc., CA.) The data were processed by a $t$-test or one-way ANOVA method with Dunnet posttest for more groups with a significance level of $P<.05$. 

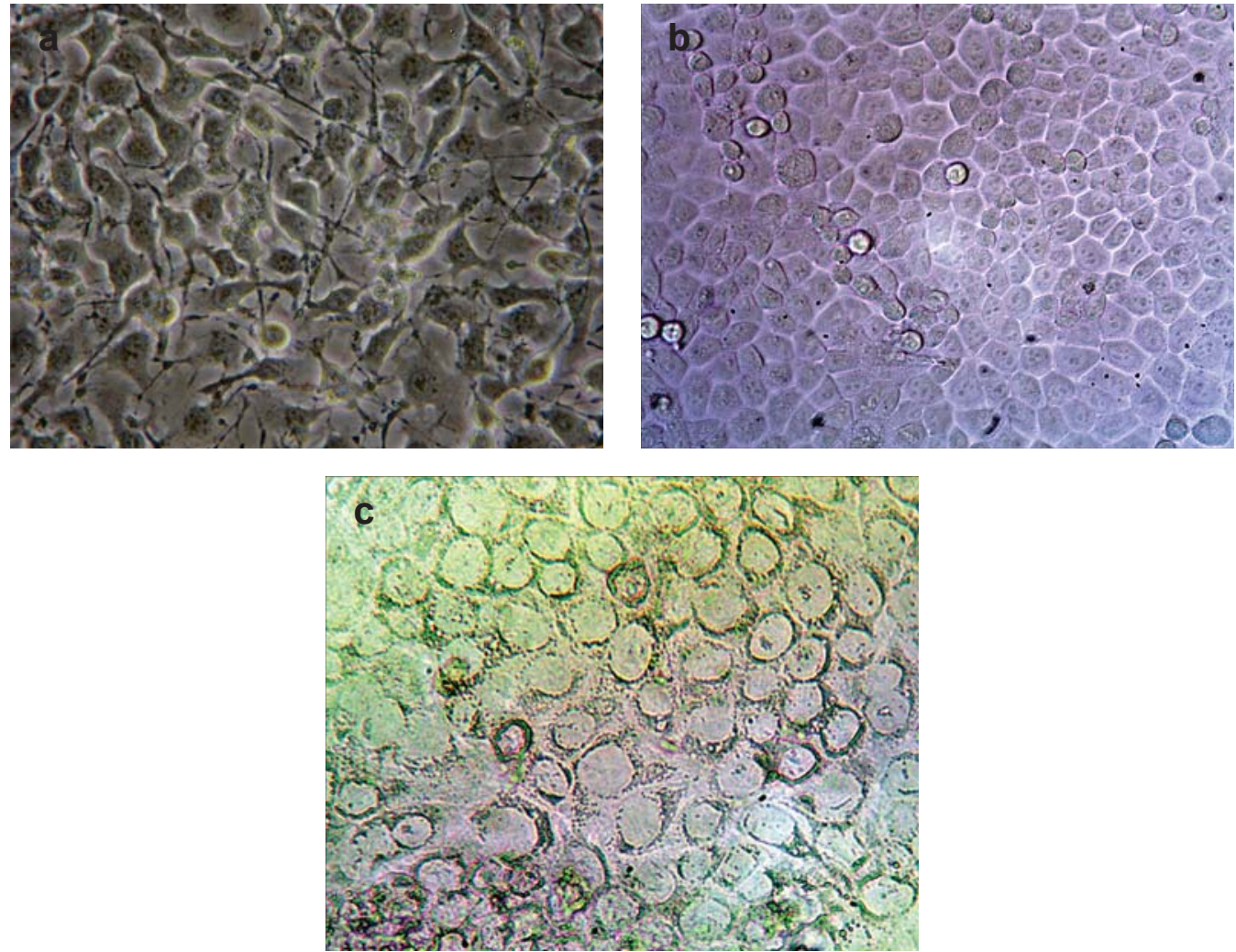

FIG. 2: Photos of (a) B16/PT, (b) HT29, and (c) HaCat (taken by Nikon Eclipse TS 100)

\section{A. Cytomorphology}

The cytomorphology of cells was observed by inversion microscopy. The living cells were recognized by their ability to adhere to the bottom of Petri dishes while nonliving cells were floating in the nourishing medium.

The cells were also colored by trypan blue for illustration of living or apoptotic cells. Trypan blue is bind to destructed cell membranes; the apoptotic cells are darker than living cells.

\section{B. XCEligence System}

xCELLigence Real Time Cell Analyzer (RTCA) system analyzes cells' behavior (i.e., dynamic processes like cell adhesion, proliferation, cytoskeletal changes, apoptosis, cytotoxic influence of drugs on cells, and viability). ${ }^{8}$ The significant advantage is observing the cells in an incubator (in their "natural" environment) in real time.

The point is to monitor cell adhesion (growing cells) in E-plates. The gold microelectrodes in the bottom of each well measure changes in impedance during cell adhesion. 
TABLE 1: B16 (PT, CTC, ASC) exposure parameters

\begin{tabular}{|c|c|c|}
\hline Sample & Exposed to & Exposure Time \\
\hline 1 & Nothing (reference sample) & - \\
\hline 2 & $1300 \mathrm{~Pa}$ & $10 \mathrm{~min}$ \\
\hline 3 & $\mathrm{O} 2+\mathrm{He}: \mathrm{NO}: \mathrm{Ar}$ & $2 \mathrm{~min}$ \\
\hline 4 & $\mathrm{O} 2(\mathrm{a} 1 \Delta \mathrm{g})+\mathrm{O} 2: \mathrm{He}: \mathrm{NO}: \mathrm{Ar}$ & $4 \mathrm{~min}$ \\
\hline 5 & $\mathrm{O} 2(\mathrm{a} 1 \Delta \mathrm{g})+\mathrm{O} 2: \mathrm{He}: \mathrm{NO}: \mathrm{Ar}$ & $6 \mathrm{~min}$ \\
\hline 6 & $\mathrm{O} 2(\mathrm{a} 1 \Delta \mathrm{g})+\mathrm{O} 2: \mathrm{He}: \mathrm{NO}: \mathrm{Ar}$ & $7 \mathrm{~min}$ \\
\hline 7 & $\mathrm{O} 2(\mathrm{a} 1 \Delta \mathrm{g})+\mathrm{O} 2: \mathrm{He}: \mathrm{NO}: \mathrm{Ar}$ & $8 \mathrm{~min}$ \\
\hline 8 & $\mathrm{O} 2(\mathrm{a} 1 \Delta \mathrm{g})+\mathrm{O} 2: \mathrm{He}: \mathrm{NO}: \mathrm{Ar}$ & $9 \mathrm{~min}$ \\
\hline 9 & $\mathrm{O} 2(\mathrm{a} 1 \Delta \mathrm{g})+\mathrm{O} 2: \mathrm{He}: \mathrm{NO}: \mathrm{Ar}$ & $10 \mathrm{~min}$ \\
\hline 10 & $\mathrm{ROS}+\mathrm{O} 2: \mathrm{He}: \mathrm{NO}: \mathrm{Ar}$ & 2 or $4 \mathrm{~min}$ \\
\hline
\end{tabular}

Impedance is denoted in cell index. We performed the test for 72 hours. After 22 hours cisplatin was added. Cisplatin is a chemotherapeutic agent used to treat melanoma. The combination of chemotherapy and singlet oxygen therapy was compared in real time.

The results are characterized by cell index, which is calculated by system. Cell index is calculated from measured electric bioimpedance, and this bioimpedance is proportional to the ratio of adhered (living) cells.

\section{Quantitative Polymerase Chain Reaction}

Gene expression testing was provided on the basis of transcripts of genes on the mRNA level. Then mRNA was transcripted to DNA. The method is called quantitative polymerase chain reaction (qPCR). In each cycle the fluorescence was measured. The value of fluorescent absorption is proportional to the amount of PCR products (in

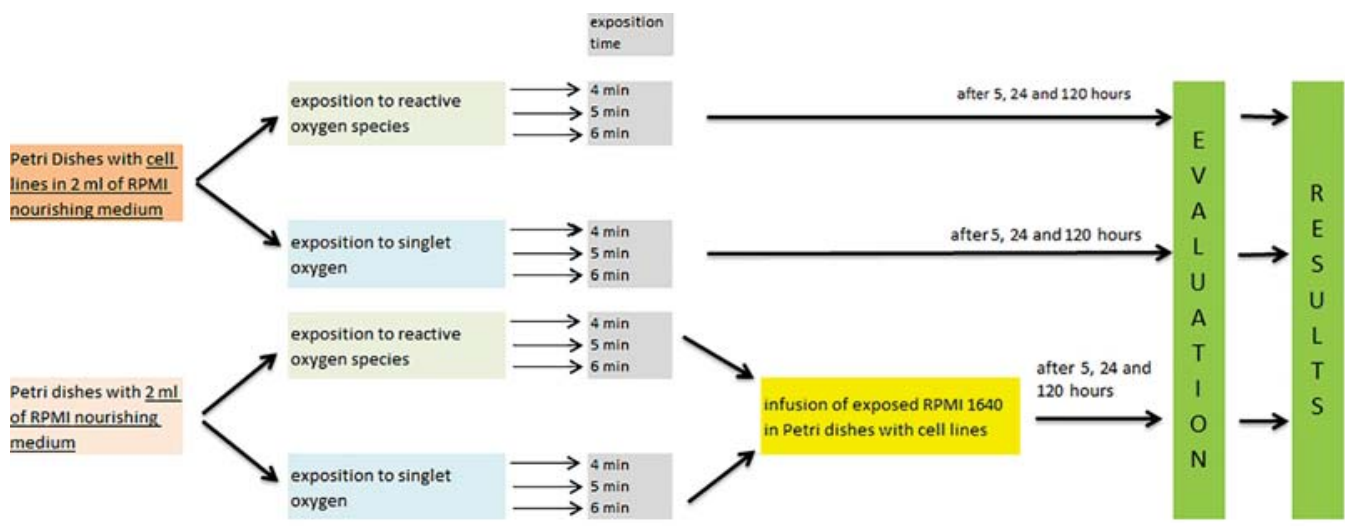

FIG. 3: Methodology of experiments

Volume 8, Issue 2, 2018 
this case, target genes). The output of this method is a relative amount of RNA that is calculated by $\Delta \Delta \mathrm{C}_{\mathrm{t}}$ method as was described by Livak. ${ }^{9}$

A value greater than 1 indicates that gene expression of the concrete gene is upregulated; a value less than 1 indicates that gene expression of the concrete gene is downregulated. The investigated genes were as follows: actin (housekeeping gene); melanin (for identification of melanoma cells); caspase 3, B-cell chronic lymphocytic leukemia, nuclear factor of kappa light polypeptide gene enhancer in B cells (for inflammation); baculoviral IAP repeat-containing and vascular endothelial growth factor A (for inhibition of apoptosis); hypoxia inducible factor 1 (for hypoxia); and cytochrome $\mathrm{C}$ oxidase assembly factor (for hyperoxia).

\section{RESULTS OF B16 CEL UNES}

Primary melanoma cells were exposed to electric-discharge-generated singlet oxygen. The highest sensitivity to singlet oxygen exposure exerted CTC/B16. The surviving cells were tested by the MTT/xCELLigence System. Cisplatin was added in selected samples. The combined effect of singlet oxygen exposure and chemotherapy has, however, a negative impact.

Based on RTCA analysis, exposure to singlet oxygen increases the resistivity of cell lines to cisplatin. Figure 4 shows that resistance to cisplatin is significantly higher after exposure to singlet oxygen. The best growth is at cells with longer exposure time to singlet oxygen and with cisplatin added.

From the results of gene expression (Table 2), it is clear that apoptotic and antiapoptotic genes are working properly. The most variable expression was in group 3 (see Table 1 for exposure times and gases), which was exposed by all discharge gases - fu-

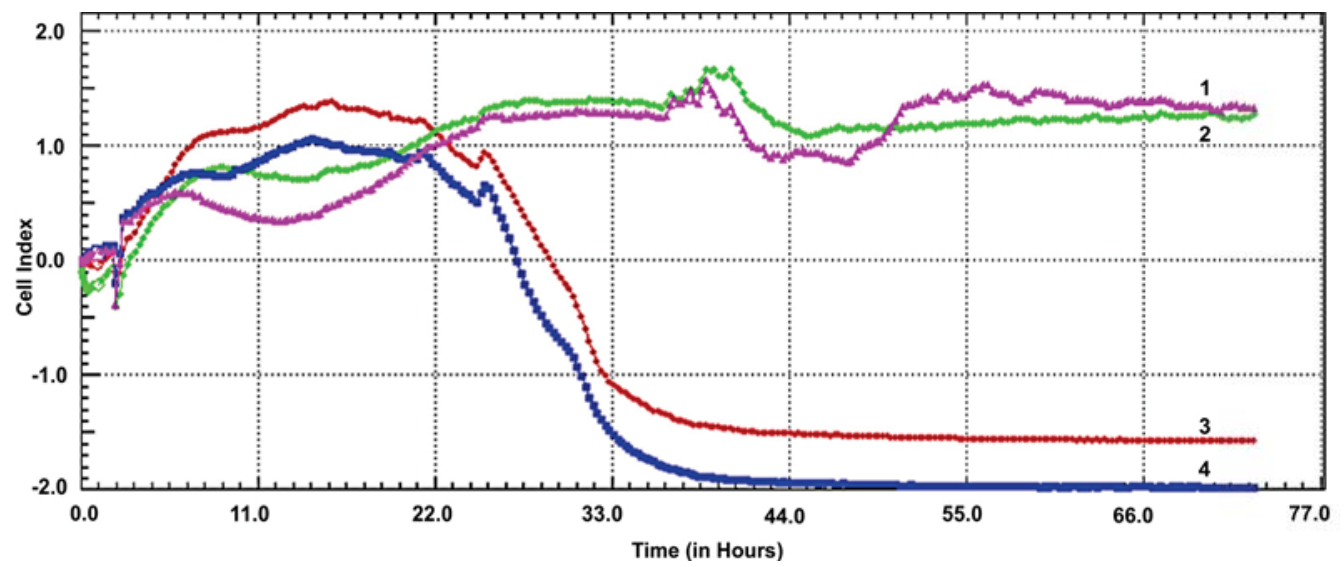

FIG. 4: Chart evaluated by SW RTCA. Line 1 illustrates cells exposed for 8 min to singlet oxygen and added cisplatin. Line 3 illustrates B16/Pt exposed to singlet oxygen for $8 \mathrm{~min}$. Line 4 illustrates exposure to singlet oxygen for $2 \mathrm{~min}$, and Line 2 is the same sample with cisplatin added. 
TABLE 2: qPCR results: relative amount of RNA calculated by $\Delta \Delta$ CT Livak's method ${ }^{9}$

\begin{tabular}{|c|c|c|c|c|c|c|c|c|}
\hline $\begin{array}{c}\text { Group } \\
\text { sample }\end{array}$ & mlana & casp3 & bcl2 & birc5 & hif1 & vegf & cox2 & nfkb1 \\
\hline 1 & 1 & 1 & 1 & 1 & 1 & 1 & 1 & 1 \\
\hline 2 & 0.82 & 1.13 & 1.02 & 1.08 & 0.69 & 0.90 & 3.94 & 0,73 \\
\hline 3 & 2.63 & 4.46 & 1.74 & 2.42 & 1.89 & 2.79 & 19.01 & 3,69 \\
\hline 4 & 0.44 & 0.88 & 0.35 & 0.64 & 0.32 & 0.38 & 0.79 & 0,85 \\
\hline 5 & 0.52 & 1.52 & 0.54 & 0.87 & 0.85 & 0.92 & 3.25 & 1,76 \\
\hline 6 & 0.95 & 1.39 & 0.33 & 0.87 & 0.50 & 0.31 & 1.84 & 1,29 \\
\hline 7 & 1.90 & 3.36 & 0.50 & 2.42 & 0.77 & 0.23 & 1.89 & 3,87 \\
\hline 8 & 1.19 & 1.88 & 0.39 & 0.95 & 0.77 & 0.64 & 1.56 & 2,53 \\
\hline 9 & 0.44 & 2.00 & 0.41 & 0.90 & 0.69 & 0.81 & 1.43 & 1,39 \\
\hline 10 & 0.41 & 1.57 & 0.40 & 1.32 & 0.52 & 0.74 & 0.58 & 1,83 \\
\hline
\end{tabular}

ture investigation into the influence of all discharge gases (in different time intervals) on different types of cells could be interesting. The most variable expression in group 3 was probably caused by the presence of NO in exposition mixture of gases. During exposure to singlet oxygen, this gas is used for atomic oxygen titration; it is not present in the exposure chamber. Sample group 7 provides extremely interesting results as well.

All samples were frozen in RLT for RNA stabilization and further analyses.

\section{CONCLUSONSAND DISCUSSION}

The pilot experiments with exposure of melanoma cell lines (B16/PT/CTC/ASC) by singlet oxygen and several other reactive species were performed. The primary results show that the singlet oxygen therapy cannot be combined with the chemotherapy (concretely with cisplatin, which is usually used for melanoma treatment). The highest sensitivity to singlet oxygen therapy was observed at circulating tumor cell lines. It is probably influenced by its mesenchymal origin.

From qPCR for B16 cell lines it is obvious that the production of apoptic primers is upregulated and the production of antiapoptic primers is downregulated. The cells are apoptic and they have inflammation after exposure. Based on the current results, "electric discharge" singlet oxygen has a potential to be used for melanoma treatment.

Furthermore, experiments comparing the influence of singlet oxygen and reactive oxygen species were carried out on the HT29 and HaCat cell lines. Cytomorphology did not show any significant difference between exposure to singlet oxygen and exposure to reactive oxygen species. However, the gene expression for this cell line is needed for a final conclusion. The cells were frozen in RLT $+\beta-M E$ for RNA stabilization, and the assay will be performed after selection of proper primers; the results for these cell lines are currently under investigation.

Volume 8, Issue 2, 2018 
In future work the differences between cell lines' response to exposure by singlet oxygen and reactive oxygen species or nitrogen species should be investigated further. Currently, the HaCat cell culture is under investigation to better understand the singlet oxygen/reactive oxygen species' influence on physiologically healthy cells and also to compare physiologically healthy cells' reaction and cancer cells' reactions on these particles.

The goal is to find the best combination of species and time intervals for every possible biomedical application (e.g., oncology treatment, wound healing) of these "afterglow discharge species."

\section{ACKNOWEDGMENTS}

This work has been supported by the Czech Science Foundation under the Grant Project P102-12-0723 and Czech Technical University in Prague under the Grant Projects SGS15/174/OHK4/2T/17 and SGS17/158/OHK4/2T/17.

\section{REERENCES}

1. Laroussi M, Kong M, Morfill G, Stolz W. Plasma medicine applications of low-temperature gas plasmas in medicine and biology. Cambridge: Cambridge University Press; 2012.

2. Pouvesle JM, Collet G, Robert E, Ridou L, Brullé L., Ries D, Vandamme M, Darny T, Dozias S, El Hafni-Rahbi B, Kieda C. Potential of plasma based soft and/or combined cancer treatments. Proceedings of 22nd International Symposium on Plasma Chemistry: 2015 Jun 5-10; Antwerp, Belgium.

3. Judeé E, Merbahi N, Plewa J-M, Yousfi M, Frongia C, Eichwald O, Ducommun, Lobjois V. Antiproliferative effects on multi-cellular tumour spheroids induces by low-temperature plasma. Proceedings of 22nd International Symposium on Plasma Chemistry: 2015 Jun 5-10; Antwerp, Belgium.

4. Woedtke T, Metelmann H-R, Lademann J, Schmidt A, Masur K, Schönebeck R, Weltmann K-D. Clinical application of cold atmospheric plasma - state and perspectives. Proceedings of 22nd International Symposium on Plasma Chemistry: 2015 Jun 5-10; Antwerp, Belgium.

5. Vodičková A, Schmiedberger J, Kološtová K. Melanoma cells and singlet oxygen generated by electric discharge. Proceedings of 22nd International Symposium on Plasma Chemistry: 2015 Jun 5-10; Antwerp, Belgium.

6. Schmiedberger, J, Jirásek V, Kodymová, J, Rohlena K. Novel concept of electric discharge oxygeniodine laser, Eur Phys J D, 2009;54(2):239-48.

7. Schmiedberger J, Rohlena K, Gregor J, Křenek P, Jirásek V, Čenský M, Kodymová J. Hybrid RF/DC plasma torch for generation of singlet oxygen in discharge oxygen-iodine laser. Proceedings SPIE 7751, XVIII International Symposium on Gas Flow, Chemical Lasers, and High-Power Lasers: 2010 Nov 16.

8. Roche Applied Science [homepage on the Internet]. The xCELLigence System: New Horizons in Cellular analysis. Roche Diagnostics GmbH; c2009 [cited 2012 May 14]. Available from: http:// www.rocheappliedscience.com/sis/xcelligence/xce_docs/xCELL-SystBrosch_NL2_LR.pdf.

9. Kenneth J Livak, Thomas D, Schmittgen D. Analysis of relative gene expression data using realtime quantitative PCR and the 2- $\Delta \Delta C$ T method. Methods. 2001;25(4):402-8. 